\title{
Antidiabetic treatment restores adiponectin serum levels and APPL1 expression, but does not improve adiponectin-induced vasodilation and endothelial dysfunction in Zucker diabetic fatty rats
}

Peter M Schmid*, Markus Resch, Christian Schach, Christoph Birner, Guenter A Riegger, Andreas Luchner and Dierk H Endemann

\begin{abstract}
Background: Adiponectin is able to induce NO-dependent vasodilation in Zucker lean (ZL) rats, but this effect is clearly alleviated in their diabetic littermates, the Zucker diabetic fatty (ZDF) rats. ZDF rats also exhibit hypoadiponectinemia and a suppressed expression of APPL1, an adaptor protein of the adiponectin receptors, in mesenteric resistance arteries. Whether an antidiabetic treatment can restore the vasodilatory effect of adiponectin and improve endothelial function in diabetes mellitus type 2 is not known.

Methods: During our animal experiment from week 11 to 22 in each case seven ZDF rats received an antidiabetic treatment with either insulin $(Z D F+I)$ or metformin $(Z D F+M)$. Six normoglycemic $Z L$ and six untreated ZDF rats served as controls. Blood glucose was measured at least weekly and serum adiponectin levels were quantified via ELISA in week 11 and 22. The direct vasodilatory response of their isolated mesenteric resistance arteries to adiponectin as well as the endothelium-dependent and -independent function was evaluated in a small vessel myograph. Additionally, the expression of different components of the adiponectin signaling pathway in the resistance arteries was quantified by real-time RT-PCR.
\end{abstract}

Results: In ZDF rats a sufficient blood glucose control could only be reached by treatment with insulin, but both treatments restored the serum levels of adiponectin and the expression of APPL1 in small resistance arteries. Nevertheless, both therapies were not able to improve the vasodilatory response to adiponectin as well as endothelial function in ZDF rats. Concurrently, a downregulation of the adiponectin receptors 1 and 2 as well as endothelial NO-synthase expression was detected in insulin-treated ZDF rats. Metformin-treated ZDF rats showed a reduced expression of adiponectin receptor 2 .

Conclusions: An antidiabetic treatment with either insulin or metformin in ZDF rats inhibits the development of hypoadiponectinemia and downregulation of APPL1 in mesenteric resistance arteries, but is not able to improve adiponectin induced vasodilation and endothelial dysfunction. This is possibly due to alterations in the expression of adiponectin receptors and eNOS.

Keywords: Adiponectin, APPL1, AdipoR, eNOS, Insulin, Metformin, Diabetes mellitus type 2

\footnotetext{
* Correspondence: peterm.schmid@ukr.de

Klinik und Poliklinik für Innere Medizin 2, Franz-Josef-Strauss Allee 11,

University of Regensburg, Regensburg 93042, Germany
} 


\section{Background}

Adiponectin is a $30-\mathrm{kDa}$ adipokine, which is predominantly and abundantly secreted form adipose tissue [1-3]. Unlike serum levels of other adipokines, levels of adiponectin characteristically correlate negatively with obesity and its comorbidities [2,4-6]. Therefore hypoadiponectinemia serves as a marker of adipose tissue dysfunction and the metabolic syndrome $[7,8]$. Adiponectin exerts insulin-sensitizing and antiinflammatory actions in liver and muscle cells $[9,10]$ and has vasoprotective effects [11-13]. Adiponectin binds at the cellular level to two specific transmembrane receptors, adiponectin receptor 1 (AdipoR1) and adiponectin receptor 2 (AdipoR2) $[14,15]$, which provokes an intracellular activation of the $5^{-}$-AMP-activated protein kinase (AMPK) and PPAR-alpha [16]. APPL1 (adaptor protein, phosphotyrosine interaction, $\mathrm{PH}$ domain and leucine zipper containing 1) is the first described adaptor protein for the adiponectin receptors [17] and seems to play an important role in the intracellular signal transmission from the receptors to AMPK and PPAR-alpha as well as in the crosstalk with the insulin signaling pathway [18-20]. In contrast, its protein isoform, APPL2 (adaptor protein, phosphotyrosine interaction, $\mathrm{PH}$ domain and leucine zipper containing 2), seems to act as a negative regulator of adiponectin signaling [21].

In the last years several studies could prove that adiponectin causes NO production in endothelial cell cultures by binding to its receptors and a consecutive activation of APPL1, AMPK and endothelial nitric oxidase (eNOS) [22-25]. Recently, we [26] could show that adiponectin indeed provokes a NO-dependent vasodilation of mesenteric resistance arteries in nondiabetic Zucker lean (ZL) rats. Additionally, this vasodilation was diminished in their diabetic littermates, the Zucker diabetic fatty (ZDF) rat, which also exhibited endothelial dysfunction. As possible pathological mechanism we found hypoadiponectinemia in ZDF rats and a downregulation of APPL1 in their mesenteric arteries at mRNA level. For this reason, we concluded that a decreased adiponectin signaling through hypoadiponectinemia and a reduced sensitivity to adiponectin is at least in part responsible for endothelial dysfunction in diabetes mellitus type 2 . This hypothesis was supported by other studies demonstrating endothelial dysfunction in hypoadiponectinemia and an improvement of endothelial function by replenishment of adiponectin levels [27-29].

In this study we wanted to test, whether an antidiabetic treatment with either insulin or metformin can improve endothelial dysfunction and restore vasorelaxation to adiponectin in ZDF rats. Further, we wanted to detect effects on the expression levels of adiponectin receptors, APPL1, APPL2 and endothelial nitric oxidase (eNOS) via real-time RT-PCR.

\section{Methods}

\section{Animal experiments}

The study was approved by the local committee on animal research and is in accordance with the "Guide for the Care and Use of Laboratory Animals" published by the US National Institutes of Health. Six male Zucker lean (ZL) rats (fa/-) and twenty male Zucker diabetic fatty (ZDF) rats $(\mathrm{fa} / \mathrm{fa})$ were studied from an age of 11 weeks until an age of 22 weeks. Of the ZDF rats, six were kept as untreated controls throughout the whole experiment, seven were treated with insulin subcutaneously $(\mathrm{ZDF}+\mathrm{I})$ and the remaining seven animals were treated with metformin solved in tap water $(\mathrm{ZDF}+\mathrm{M})$. In the insulin group blood glucose was measured every second day after 6 hours fasting (ACCU-CHEK Sensor, Roche GmbH, Mannheim, Germany). Treatment target was to reach nearly normal blood glucose levels. Therefore the insulin dose was adjusted to the last blood glucose value prior to the planned insulin administration. Blood glucose in the metformin group was quantified twice a week and metformin dose was increased from initially 300 up to $600 \mathrm{mg} / \mathrm{kg} /$ day as the maximum tolerable concentration without severe toxic side effects for rats [30]. Blood glucose in untreated ZDF and ZL rats was measured weekly. Animals were individually housed on a 12-hour dark/12-hour light cycle. They were fed a Purina 5008 rat chow containing 23\% protein, $6.5 \%$ fat, $58.5 \%$ carbohydrates, $4 \%$ fiber and $8 \%$ ash. Rats received tap water ad libitum. At baseline (week 11) and in the last week (week 22) serum levels of adiponectin were measured (B-Bridge International, Inc., Mountain View, USA) via ELISA according to the instructions of the manufacturer. Systolic blood pressure as well as heart rate was assessed every two weeks by tail cuff method using an automated cuff inflator-pulse detection system (CODA2 Multi-Channel, Computerized, EMKA TECHNOLOGIES, Paris, France). Body weight was measured weekly. At the end of the experiment animals were sacrificed and the mesenteric vasculature was dissected for preparation of small resistance arteries.

\section{Preparation and study of small resistance arteries}

As described previously [26], a third-order branch from the mesenteric artery of the different investigated rats was prepared and mounted on a pressure myopraph (DMT, Aarhus, Danmark). First, the vessels media thickness and the lumen diameters were measured. Then, after precontraction with norepinephrine $\left(10^{-5} \mathrm{~mol} / \mathrm{L}\right)$, endotheliumdependent and independent relaxation was assessed with acetylcholine (ACh) $\left(10^{-9}-10^{-4} \mathrm{~mol} / \mathrm{L}\right)$ and sodium nitroprusside (SNP) $\left(10^{-5}-10^{-2} \mathrm{~mol} / \mathrm{L}\right)$, respectively. Also, the endothelial vasodilator function of adiponectin was quantified after precontraction with norepinephrine $\left(10^{-5} \mathrm{~mol} / \mathrm{L}\right)$ by a stepwise administration of globular adiponectin in 
cumulative concentrations from 0.03125 to $0.5 \mu \mathrm{g} / \mathrm{ml}$ ) (AXXORA GmbH, Lörrach, Germany). The NOdependency of the observed vasodilatory response to adiponectin was tested by an additional preincubation and application of L-nitroarginine-methyl-ester (L-NAME) $\left(10^{-5} \mathrm{~mol} / \mathrm{L}\right)$, an inhibitor of the endothelial NO synthase (eNOS).

In all experiments the vasodilation of the vessels was calculated as percentage after a maximal precontraction with $10^{-5} \mathrm{~mol} / \mathrm{L}$ norepinephrine using the following formula: vasodilation $(\%)=\left(D_{\mathrm{X}}-\mathrm{D}_{\mathrm{NE}}\right) /\left(\mathrm{D}_{\mathrm{R}}-\mathrm{D}_{\mathrm{NE}}\right) \times 100$. Thereby $\mathrm{D}_{\mathrm{X}}$ is the actual measured diameter at a given concentration of adiponectin, ACh or SNP. $D_{\mathrm{NE}}$ is the diameter under precontration with norepinephrine, and $D_{R}$ is the resting diameter of the vessel.

\section{Expression of adiponectin receptors, APPL1, APPL2 and eNOS}

The expression of the adiponectin receptors, AdipoR1 and AdipoR2, the adaptor proteins, APPL1 and APPL2, as well as the expression of eNOS in the small arteries was measured by using a real-time RT-PCR. Therefore, same calibre branches of the mesenteric artery were collected and cleaned from adipose and connecting tissue. Total RNA was extracted using RNeasy kit (Quiagen, Hilden, Germany) according to the instructions of the manufacturer. For first-strand cDNA synthesis, $1 \mu \mathrm{g}$ total RNA was reverse transcribed with $1 \mathrm{U}$ MMLV Reverse Transcriptase, $1 \mu \mathrm{g}$ Random Primer, $1 \mathrm{mM}$ deoxynucleotide triphosphate mixture, $1 \mu \mathrm{l}$ recombinant $\mathrm{RNasin}^{\circledR}$ ribonuclease inhibitor and transcription buffer with $5 \mathrm{mM}$ $\mathrm{MgCl}_{2}$ in a final volume of $10 \mu \mathrm{l}$ (all from Promega, Mannheim, Germany). The reaction mixture was incubated at $37^{\circ} \mathrm{C}$ for $60 \mathrm{~min}$, followed by heat inactivation of the enzyme at $95^{\circ} \mathrm{C}$ for $5 \mathrm{~min}$. After cooling on ice for 5 min, the cDNA was stored at $-20^{\circ} \mathrm{C}$. In parallel, $1 \mu \mathrm{g}$ total RNA was processed without reverse transcription to control for contamination with genomic DNA. Real-time RT-PCR detection of AdipoR1, AdipoR2, APPL1, APPL2 and eNOS was carried out using the AbiPrism 7900 TaqMan (Applied Biosystems, Foster City; CA, USA). Beta-actin was used as housekeeping gene for normalization. The TaqMan probes for AdipoR1, AdipoR2, eNOS, iNOS, and for beta-actin were purchased from Applied Biosystems (Foster City, USA). Primers for APPL1 and APPL2 bridging at least one intron were designed and purchased from MWG-Operon (Ebersberg, Germany) as described previously [26].

\section{Statistical analysis}

From the assessed biometric data, the levels of serum parameters and the relative mRNA expressions the means of every measurement for each animal group were calculated. The groups were compared using one- way ANOVA with Holm-Sidak or Fisher LSD method as post hoc test. Outliers were detected and excluded with the Nalimov test. The curves created from the measurements in the small vessel myograph were compared using two-way ANOVA for repeated measurements with Holm-Sidak method as post hoc test. All data are presented as means \pm SEM. A p-value of $<0.05$ was considered to be significant.

\section{Results}

\section{Biometric data and blood glucose levels of ZL and ZDF} rats

Table 1 shows the biometric data of different animal groups exemplarily at the beginning and the end of the experiment. In week $12 \mathrm{ZL}$ rats were significantly lighter than diabetic ZDF rats. Under the fed high-caloric diet in the course of the animal experiment ZL rats gained about $25 \%$ of weight and it was equal to untreated and metformin-treated ZDF rats in the following weeks, which also showed a slight weight gain during the experiment. In contrast, insulin-treated ZDF rats rapidly and excessively increased their body weight by about $60 \%$ until week 22 due to anabolic effects of insulin. Consecutively, their weight was significantly higher than in the other animal groups at the end of the experiment. Considering the systolic blood pressure, significant differences could be detected only in week 12 with a higher blood pressure in ZL in comparison to ZDF rats. In the following weeks the blood pressure equalized between the groups. During the whole experiment heart rate was significantly higher in ZL rats than in untreated and metformin-treated ZDF rats. Insulin-treated ZDF rats showed higher heart rates in comparison to the other diabetic animal groups only in week 12 .

Table 1 also depicts blood glucose levels in week 11 and 22. As expected, ZDF rats exhibited already at an age of 12 weeks significantly elevated blood glucose levels in terms of diabetes mellitus type 2. In contrast, ZL rats had normal blood glucose during the experiment. Concurrently, it got obvious that treatment with metformin even in highest tolerable doses had no relevant effect on blood glucose levels. Only treatment with insulin could decrease blood glucose to normal levels even though they were still slightly higher than in ZL rats. Adiponectin serum levels were similar at the beginning of the experiment (ZL $4.1 \pm 0.1 \mu \mathrm{g} / \mathrm{ml}$; ZDF $3.8 \pm$ $0.4 \mu \mathrm{g} / \mathrm{ml} ; \mathrm{ZDF}+\mathrm{I} 4.0 \pm 0.5 \mu \mathrm{g} / \mathrm{ml} ; \mathrm{ZDF}+\mathrm{M} 4.2 \pm 0.3 \mu \mathrm{g} / \mathrm{ml}$. $\mathrm{p}=0.929$ ). In the next weeks adiponectin levels decreased only in untreated ZDF rats, while they were stable in nondiabetic ZL rats and insulin- as well as metformintreated ZDF rats. This resulted in a significant hypoadiponectinemia of ZDF rats in comparison to all other animal groups in week 22 (Figure 1). 
Table 1 Biometric data and blood glucose levels

\begin{tabular}{|c|c|c|c|c|c|}
\hline Parameters & $\begin{array}{c}\text { ZL } \\
(n=6)\end{array}$ & $\begin{array}{c}\text { ZDF } \\
(n=6)\end{array}$ & $\begin{array}{l}\text { ZDF+I } \\
(n=7)\end{array}$ & $\begin{array}{c}\text { ZDF+M } \\
(n=7)\end{array}$ & $\mathrm{p}$ \\
\hline Body Weight at Week 12 [g] & $333 \pm 10^{*}$ & $367 \pm 11$ & $376 \pm 6$ & $377 \pm 10$ & 0.001 \\
\hline Body Weight at Week 22 [g] & $415 \pm 14$ & $410 \pm 15$ & $603 \pm 10+$ & $425 \pm 14$ & 0.001 \\
\hline SBP at Week $12[\mathrm{mmHg}]$ & $151 \pm 6 \S$ & $118 \pm 3$ & $128 \pm 5$ & $125 \pm 6$ & 0.002 \\
\hline SBP at Week $22[\mathrm{mmHg}]$ & $137 \pm 6$ & $129 \pm 7$ & $125 \pm 3$ & $136 \pm 2$ & 0.425 \\
\hline Heart Rate at Week 12 [bpm] & $595 \pm 16 \#$ & $471 \pm 26$ & $543 \pm 12 ¥$ & $475 \pm 18$ & 0.001 \\
\hline Heart Rate at Week 22 [bpm] & $549 \pm 14 \bar{\top}$ & $460 \pm 17$ & $489 \pm 12$ & $465 \pm 23$ & 0.023 \\
\hline Blood Glucose at Week 11 [mg/dl] & $77 \pm 4 \sim$ & $245 \pm 15$ & $239 \pm 8$ & $226 \pm 9$ & $<0.001$ \\
\hline Blood Glucose at Week 22 [mg/dl] & $75 \pm 3 \Phi$ & $259 \pm 17$ & $106 \pm 109$ & $231 \pm 24$ & $<0.001$ \\
\hline
\end{tabular}

Abbreviations: ZL Zucker lean rats, ZDF Zucker diabetic fatty rats, ZDF+l Zucker diabetic fatty rats treated with insulin, ZDF+M Zucker diabetic fatty rats treated with metformin, $S B P$ systolic blood pressure. $p$ p-value for one-way ANOVA.

Post hoc testing: * $p<0.001$ vs. ZDF, ZDF+I and ZDF+M. $\dagger p<0.001$ vs. ZL, ZDF+I and ZDF+M. § $p<0.001$ vs. ZDF, $p=0.002$ vs. ZDF+M, $p=0.005$ vs. ZDF+l. \# $p<$ 0.001 vs. $Z D F$ and $Z D F+M . ~ ¥ p=0.011$ vs. ZDF, $p=0.009$ vs. $Z D F+M . \bar{T} p=0.005$ vs. $Z D F, p=0.007$ vs. ZDF+M. $\sim p<0.001$ vs. ZDF, ZDF+l and ZDF+M. $\Phi p<0.001$ vs. ZDF and $Z D F+M$. $\uparrow \mathrm{p}<0.001$ vs. ZDF and $Z D F+M$.

\section{Relaxation response to adiponectin}

The vasodilation response of small resistance arteries to adiponectin was tested after precontraction with norepinephrine (Figure 2). We found a dose dependent vasodilatory response for adiponectin especially in normoglycemic ZL rats. Maximum vasodilation was reached at a concentration of $0.5 \mu \mathrm{g} / \mathrm{ml}$ adiponectin with $30 \pm 4 \%$ in ZL rats. In contrast, vasodilation in ZDF rats was clearly blunted, but a slight vasodilation could also be detected with a maximum vasodilation of $18 \pm 2 \%$ at highest used concentrations of adiponectin. Of notice, treatment with insulin or metformin did not improve vasodilatory response to adiponectin in small resistance arteries (maximum vasodilation: $\mathrm{ZDF}+\mathrm{I} 19 \pm 3 \% ; \mathrm{ZDF}+\mathrm{M} 17 \pm 3 \%$ ). Only differences between $\mathrm{ZL}$ and ZDF rats irrespective of treatment were statistically significant. To test, whether the observed vasodilatory response of the small arteries to adiponec-

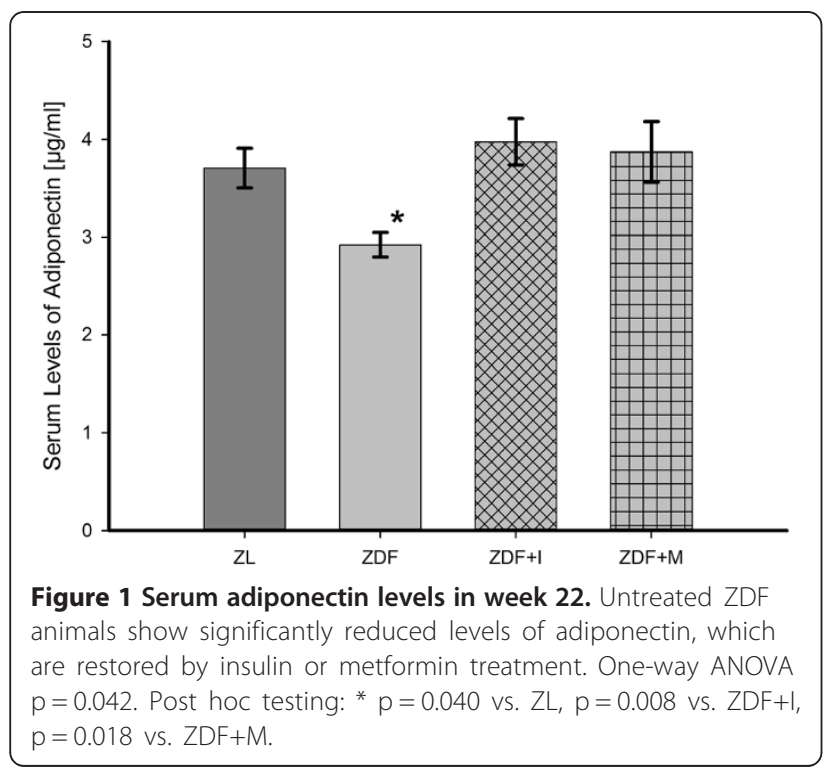

tin is NO dependent, small arteries were treated with L-NAME, an inhibitor of eNOS, additionally to adiponectin. Thereby, the initially noted vasodilatory effect of adiponectin was completely blunted (Figure 3 ). This indicates that the vasodilatory effect of adiponectin is mediated by NO.

\section{Relaxation response to acetylcholine and sodium nitroprusside}

Endothelial function was assessed by stimulation of small resistance arteries with $\mathrm{ACh}$ after precontraction with norepinephrine (Figure 4). We found a clear dose-dependent vasodilation with a maximum relaxation of $92 \pm 4 \%$ for ZDL rats at a concentration of $10^{-4} \mathrm{~mol} / \mathrm{L} \mathrm{ACh}$. This was diminished in all diabetic animals regardless of treatment,

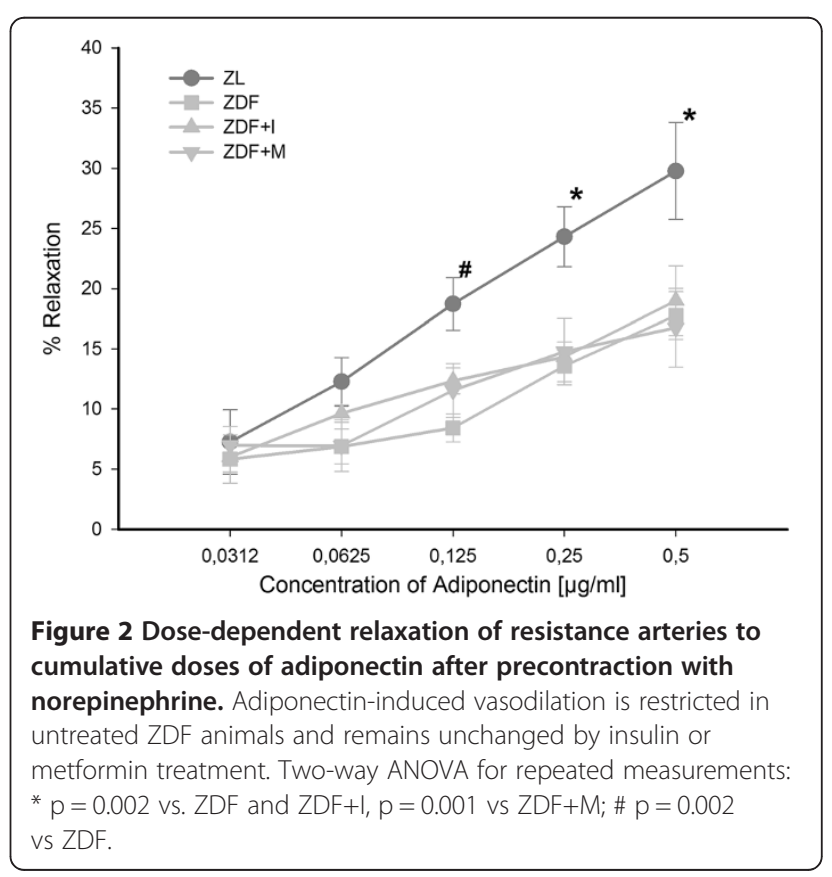




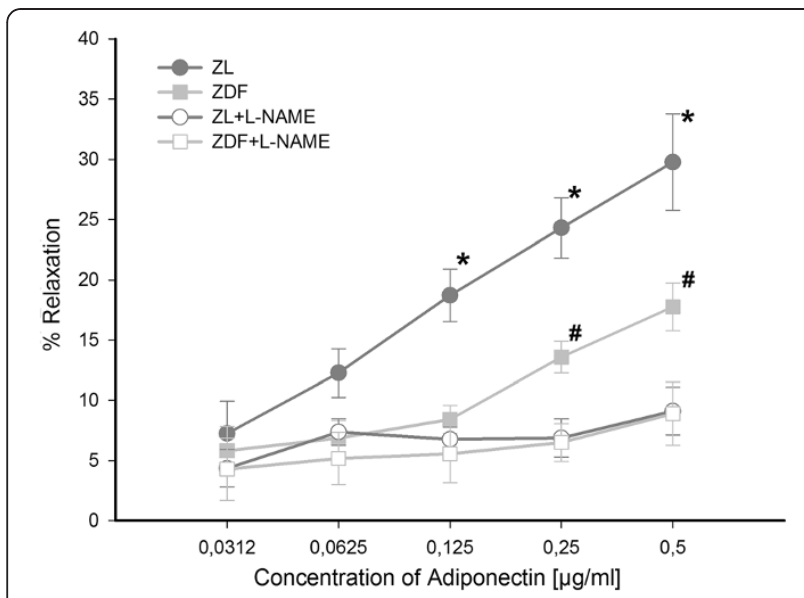

Figure 3 Dose-dependent relaxation of resistance arteries to cumulative doses of adiponectin with and without L-NAME after precontraction with norepinephrine exemplary for $\mathrm{ZL}$ and ZDF rats. Adiponectin-induced vasodilation is nearly totally blunted by L-NAME indicating NO-dependency of vasodilation. Two-way ANOVA for repeated measurements: * $p<0.001$ vs. ZL+L-NAME; \# $p<0.001$ vs. ZDF+L-NAME.

indicating endothelial dysfunction in these animals (maximum vasodilation $\mathrm{ZDF} 47 \pm 7 \%$; $\mathrm{ZDF}+\mathrm{I} 58 \pm 10 \%$; $\mathrm{ZDF}+\mathrm{M}$ $43 \pm 10 \%)$.

Endothelium-independent vasodilation was assessed by treatment with SNP (data not shown). Again, vasodilation was dose-dependent and tended to be lower in diabetic rats, but the difference between $\mathrm{ZL}$ and untreated ZDF rats was not statistically significant.

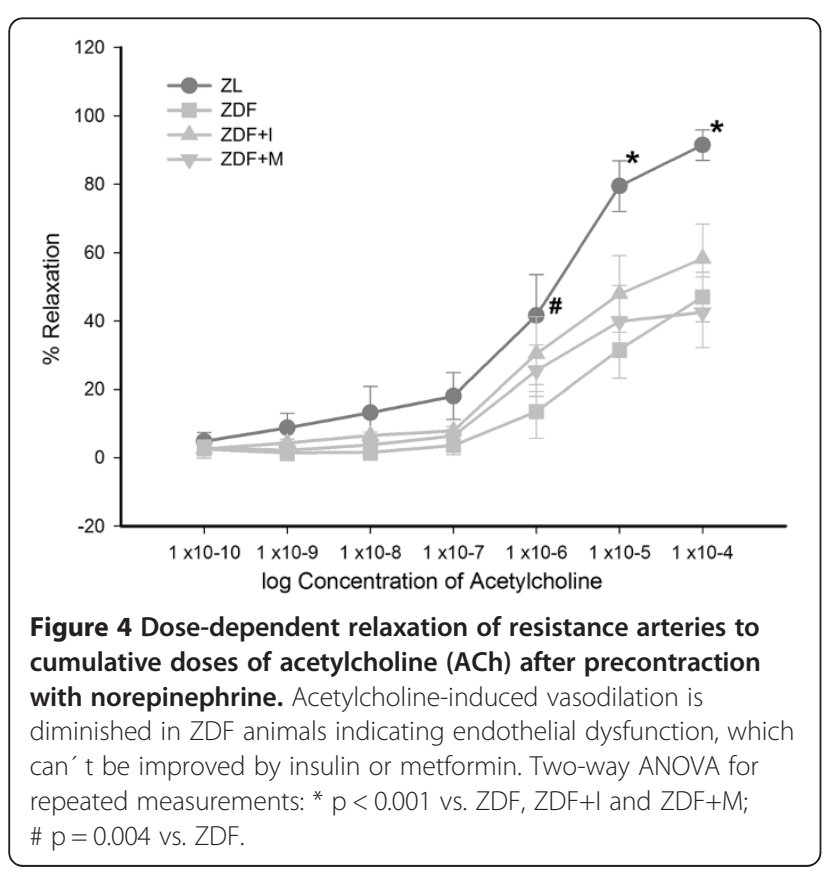

Expression of adiponectin receptors, APPL1, APPL2, and eNOS in mesenteric resistance arteries

The expression of different essential components of the adiponectin signaling pathway was measured in the mesenterial arteries by real-time RT-PCR to reveal possible causes of a different vasorelaxation response to adiponectin. Thus we performed an expression analysis for the adiponectin receptors (AdipoR1 and AdipoR2), the adiponectin receptor adaptor proteins (APPL1 and APPL2), and eNOS.

We found that AdipoR1 (Figure 5a) is expressed in a similar amount in ZL and ZDF rats. Insulin provoked a significant decrease in AdipoR1 expression in comparison to untreated ZDF rats, while in metformin-treated animals AdipoR1 expression remained unchanged. Likewise, the expression of AdipoR2 (Figure 5b) was similar in ZL and ZDF rats, but treatment with either insulin or metformin caused a significant decrease. Overall APPL1 expression (Figure 6) was lowest in untreated ZDF rats. Its expression was significantly increased by metformin and insulin. Also, in ZL rats APPL1 expression was significantly higher than in untreated ZDF rats. However, no significant differences could be detected for the expression of APPL2. Its expression was highest in insulin-treated (ZDF+I $1.1 \pm 0.12)$ and lowest in untreated and metformin-treated ZDF rats (ZDF $0.89 \pm$ $0.05 ; \mathrm{ZDF}+\mathrm{M} 0.79 \pm 0.05)$, but the differences in both cases did barely not reach the significance level $(\mathrm{p}=0.09$ vs. ZDF; $\mathrm{p}=0.057$ vs. $\mathrm{ZDF}+\mathrm{M})$.

eNOS expression in small resistance arteries (Figure 7) was similar high in ZL and untreated ZDF rats. Treatment with insulin significantly decreased the expression of eNOS, while treatment with metformin did not affect the expression of eNOS.

\section{Discussion}

The major findings of our present study are: (1) an antidiabetic treatment with insulin or metformin inhibits the development of hypoadiponectinemia and downregulation of APPL1 in ZDF rats, but (2) both treatments are not able to improve adiponectin-induced vasodilation and endothelial dysfunction; (3) treatment with insulin is able to control blood glucose levels in ZDF rats, but (4) causes a decrease of AdipoR1, AdipoR2 and eNOS expression in small mesenteric resistance arteries; (5) treatment with metformin even in highest tolerable doses does not decrease blood glucose levels in ZDF rats and (6) reduces expression of AdipoR2 in mesenteric arteries.

\section{Effect of antidiabetic treatment on adiponectin-induced vasodilation and endothelial function}

In our recent study [26] we found that adiponectin provokes a NO-dependent vasodilation of mesenterial 


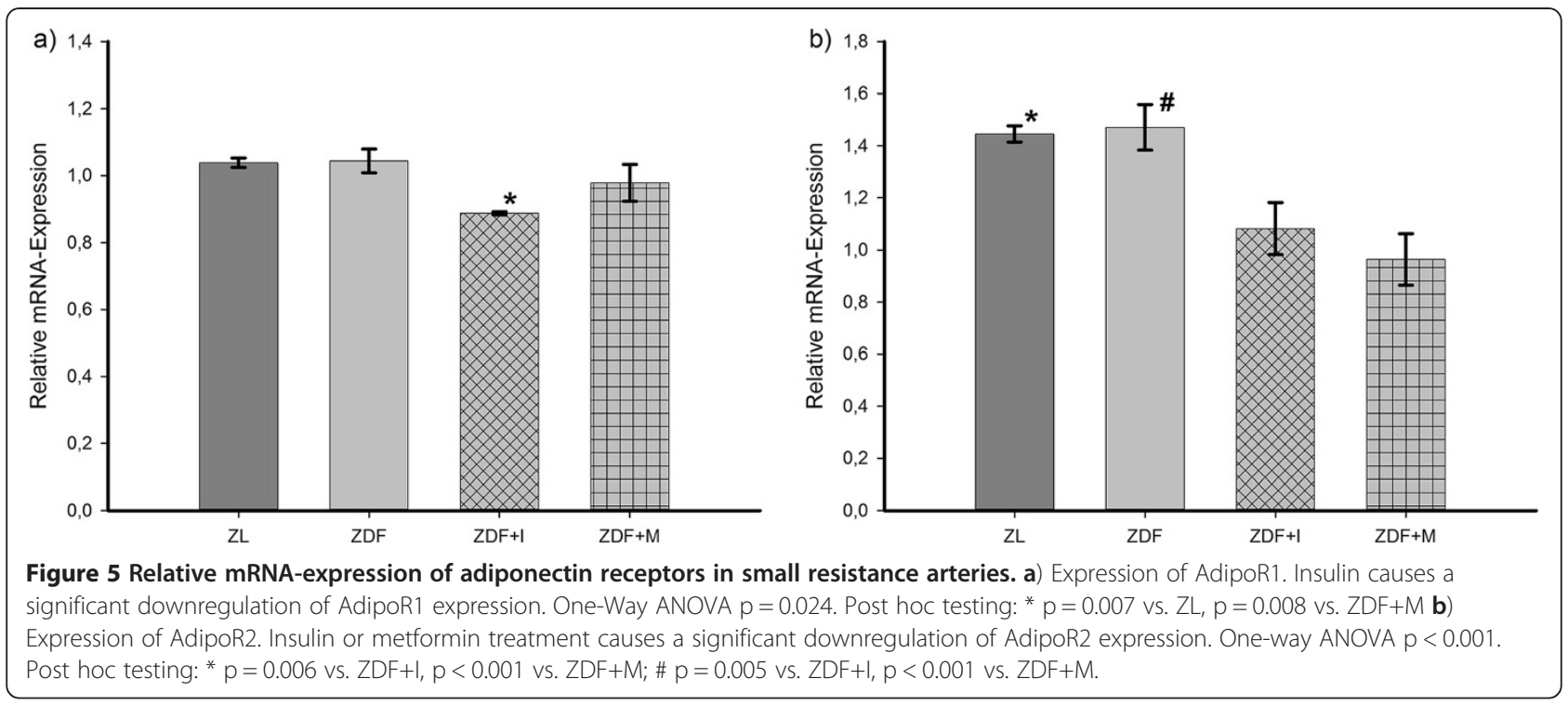

resistance arteries in $\mathrm{ZL}$ rats, which is diminished in arteries of ZDF rats. The expression analysis of different components of the adiponectin signaling pathway showed a significant downregulation of APPL1 in mesenteric arteries of ZDF rats. In addition ZDF rats exhibited hypoadiponectinemia and endothelial dysfunction. Therefore, we concluded that hypoadiponectinemia itself and a reduced intracellular adiponectin signaling are partly responsible for endothelial dysfunction in diabetes mellitus type 2 . This hypothesis was supported by a study of Ouchi et al. [29], who found that adiponectinknockout mice exhibit endothelial dysfunction and another study of Cao et al. [27], in which a replenishment of adiponectin in knock-out mice normalized endothelial function. Similar Deng et al. [28] could show that

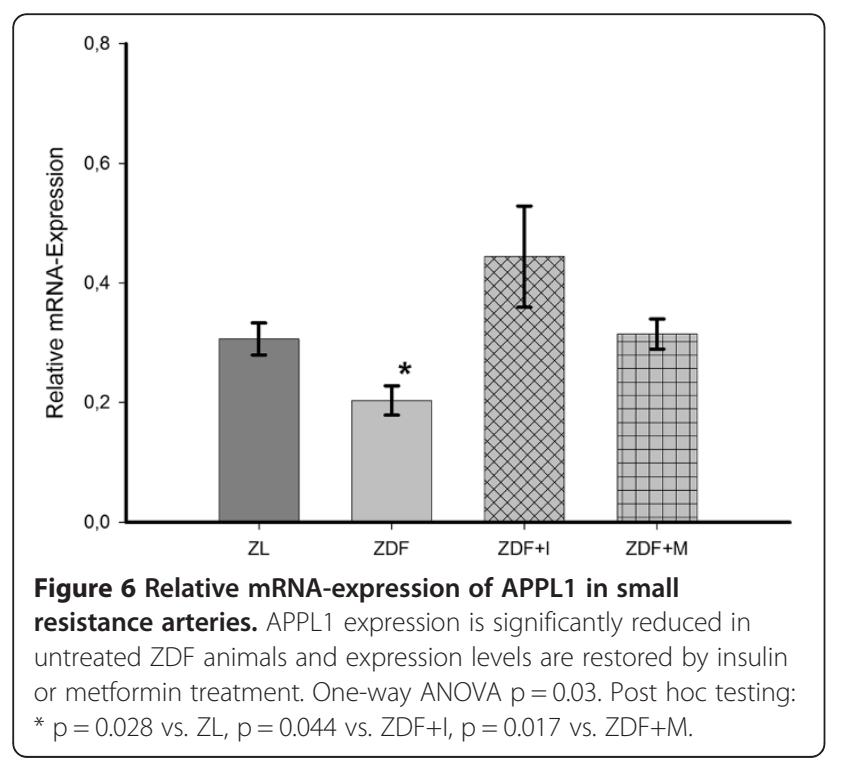

endothelial dysfunction in high-fat diet fed rats was ameliorated by an in vitro incubation of aortic rings with globular adiponectin in high doses. Therefore interventions directed to increase adiponectin levels in diabetes mellitus type 2 are possibly able to improve endothelial function. Against our expectations in the present study an antidiabetic treatment with insulin or metformin could not improve the vasodilatory effect of adiponectin and endothelial function in diabetic ZDF rats (Figure 2+4), although both restored adiponectin levels and also increased the expression of APPL1 in ZDF rats to levels of nondiabetic ZL rats (Figure $1+6$ ). Thereby, it has to be mentioned that these results of course only apply to our ex vivo setting and that we can't make a statement to possible in vivo effects of the tested antidiabetic treatment.

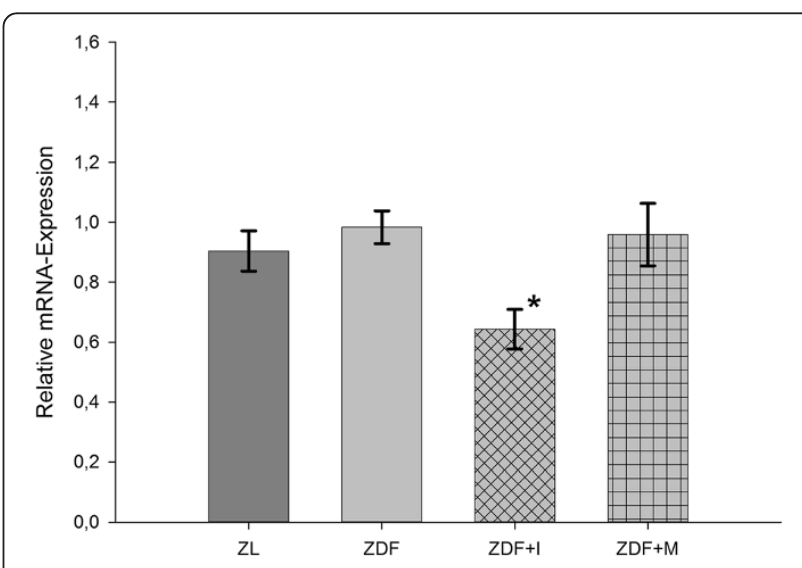

Figure 7 Relative mRNA-expression of eNOS in small resistance arteries. Insulin causes a significant downregulation of eNOS expression. One-way ANOVA $p=0.047$. Post hoc testing: * $p=0.048$ vs. $Z L, p=0.01$ vs. $Z D F, p=0.016$ vs. $Z D F+M$. 
In insulin-treated animals the reason is probably the observed downregulation of both adiponectin receptors (Figure 5) and eNOS (Figure 7), which with their localization at the beginning and end of the adiponectin signaling pathway are the main regulators of adiponectin sensitivity and NO-production. Therefore, the reduced expression of the adiponectin receptors and eNOS might diminish the benefical effects of increased adiponectin serum and APPL1 expression levels. Additionally, the increase of APPL1 expression might be counteracted by the complementary increase of APPL2 expression, even if not statistically significant. The fact that an early treatment with insulin in diabetes mellitus type 2 does not improve endothelial function is in line with a recent study in human, in which flow-mediated dilation remained unchanged after initiation of insulin therapy [31].

For metformin-treated animals our study suggests two possible reasons for the absent improvement of vasodilation. On the one hand the reduced expression of AdipoR2 (Figure 5b) and on the other hand the uncontrolled blood glucose levels. Thereby, decreased expression of AdipoR2 may at least in part reduce adiponectin sensitivity resulting in decreased eNOS activation and $\mathrm{NO}$ production. The fact that metformin is not able to control blood glucose in ZDF rats was already observed in another study, since ZDF rats develop insulin deficiency between an age of 14 and 21 weeks [32]. An uncontrolled diabetes mellitus may cause endothelial dysfunction through additional mechanisms apart from adiponectin signaling. Accordingly, a study in another rat model of diabetes mellitus type 2 showed an improvement of endothelial function in aortic rings after metformin therapy, but this effect was associated with a significant improvement of blood glucose levels [33]. However, in another experiment metformin therapy improved endothelial function independent of a blood glucose lowering effect, but this study was performed in streptozotocin-induced diabetic rats, a model of diabetes mellitus type 1 [34].

\section{Effect of antidiabetic treatment on adiponectin levels and expression of components of the adiponectin signaling pathway}

As mentioned above, both antidiabetic treatments inhibited the development of hypoadiponectinemia during the animal experiment (Figure 1).

Generally, the effect of insulin on adiponectin serum levels is contentious. In vitro, insulin inhibits the expression of adiponectin at mRNA level [35], but then it leads to an increased adiponectin secretion from adipocytes $[36,37]$. In vivo, there is a good documented association of hypoadiponectinemia with insulin resistance and diabetes mellitus type 2 [38], but the effect of insulin therapy on serum levels of adiponectin is not well studied so far. A study in five healthy male volunteers showed a decrease of adiponectin levels during a hyperinsulinemic euglycemic clamp [39]. Another study with insulin treatment in a murine model of obesity and diabetes mellitus type 2 , the $\mathrm{db} / \mathrm{db}$ mice, suggested no impact on adiponectin levels [40]. A recent study indicates an elevation of adiponectin levels in a hyperinsulinemia rat model [41]. In this respect, our study supports new evidence for a positive effect of insulin therapy on adiponectin levels despite of an increase in body weight.

For the effect of metformin on adiponectin levels there are more studies available. In vitro metformin increased the expression and secretion of adiponectin in human adipose tissue samples [42]. However, results of studies in humans with metformin treatment for different diseases showed mostly no effect on adiponectin serum levels [43-48], but it also exists evidence for an adiponectinraising effect [49-51]. In this context our animal study supports a benefical effect of metformin on adiponectin levels.

Considering the adiponectin receptors, we found under insulin treatment a significantly decreased expression of AdipoR1 and AdipoR2 compared to untreated animals (Figure 5). On this so far data from an in vitro study exist showing a reduced expression of both adiponectin receptors in skeletal and vascular smooth muscle cells by insulin [52]. Another recent study also revealed that an insulin infusion in a rat model decreased expression of AdipoR1 in skeletal and myocardial muscle [41]. This effect seems to be mediated by a direct repressive effect of insulin on the promoter activity of AdipoR1 [53]. Our data match these studies and further support and expand these findings to the vasculature. The effect of metformin on adiponectin receptor expression was so far studied in adipose tissue, skeletal muscle and liver of ZDF rats [32]. In this experiment a significant increase for both receptors in skeletal muscle was detected and our study now expands these findings with expression data for small mesenteric resistance arteries showing a decreased expression of AdipoR2.

To our knowledge, with the present study we provide first data on the effect of an antidiabetic treatment on the expression of APPL1 and APPL2 showing that insulin as well as metformin is able to increase the expression of APPL1 in resistance arteries of ZDF rats, while APPL2 expression remained unchanged (Figure 6).

In respect to eNOS, we found that insulin treatment significantly reduced its expression in mesenteric arteries (Figure 7). This goes with findings of Zanetti et al., who showed that an overexpression of eNOS in diabetic animal model can be attenuated by insulin treatment [54]. However, another study in ZDF rats found no effect of an insulin therapy on eNOS expression in the aorta [55]. Metformin treatment did not alter eNOS expression in 
our experiment, which is in line with studies in other animal models of diabetes mellitus [56].

However, our expression analyses are performed with real-time RT-PCR and therefore only reflect expression at mRNA level, since second order mesenteric arteries of rats do not yield enough protein for a reliable western blot analysis.

\section{Conclusion}

ZDF rats as a model of diabetes mellitus type 2 are characterized by hypoadiponectinemia, a reduced expression of APPL1 and a decreased response of their mesenteric arteries to adiponectin and acetylcholine in terms of endothelial dysfunction. In our present study, we explored the effect of an antidiabetic treatment with insulin or metformin on their endothelial function and the expression of different components of the adiponectin signaling pathway. We found that both treatments restored adiponectin serum levels and expression of APPL1 in small mesenteric resistance arteries, but were not able to improve endothelial function. This is possibly due to a reduced expression of AdipoR1, AdipoR2 and eNOS under insulin treatment and a reduced expression of AdipoR2 and uncontrolled blood glucose under metformin therapy in our animal model. Since the phenotype of type 2 diabetes mellitus in the ZDF animal model is based on a homozygous mutation in the leptin receptor, our results can only be applied with restrictions to humans. In addition, it can't be excluded that our results are at least in part influenced by the genetic difference between ZL and ZDF rats.

\section{Competing interests}

The authors declare that they have no competing interests.

\section{Authors' contributions}

$P S, M R$ and DE designed research; PS, MR, CS, CB and DE performed research; GR and AL revised the manuscript critically for intellectual content; PS and DE analyzed data; PS and DE wrote the paper. All authors have read and approved submission of the final manuscript.

\section{Acknowledgments}

The authors wish to thank Gabriela Pietrzyk, University Hospital of Regensburg, for excellent technical assistance. The study was supported by the "Regensburger Forschungsförderung in der Medizin" (ReForM A).

Received: 21 January 2013 Accepted: 12 March 2013

Published: 18 March 2013

\section{References}

1. Scherer PE, Williams S, Fogliano M, Baldini G, Lodish HF: A novel serum protein similar to $\mathrm{C} 1 \mathrm{q}$, produced exclusively in adipocytes. J Biol Chem 1995, 270(45):26746-26749

2. Hu E, Liang P, Spiegelman BM: AdipoQ is a novel adipose-specific gene dysregulated in obesity. J Biol Chem 1996, 271(18):10697-10703.

3. Maeda K, Okubo K, Shimomura I, Funahashi T, Matsuzawa Y, Matsubara K: CDNA cloning and expression of a novel adipose specific collagen-like factor, apM1 (AdiPose Most abundant Gene transcript 1). Biochem Biophys Res Commun 1996, 221(2):286-289.

4. Yatagai T, Nagasaka S, Taniguchi A, Fukushima M, Nakamura T, Kuroe A, Nakai Y, Ishibashi S: Hypoadiponectinemia is associated with visceral fat accumulation and insulin resistance in Japanese men with type 2 diabetes mellitus. Metabolism 2003, 52(10):1274-1278.
5. Basu R, Pajvani UB, Rizza RA, Scherer PE: Selective downregulation of the high molecular weight form of adiponectin in hyperinsulinemia and in type 2 diabetes: differential regulation from nondiabetic subjects. Diabetes 2007, 56(8):2174-2177

6. Arita Y, Kihara S, Ouchi N, Takahashi M, Maeda K, Miyagawa J, Hotta K, Shimomura I, Nakamura T, Miyaoka K, et al: Paradoxical decrease of an adipose-specific protein, adiponectin, in obesity. Biochem Biophys Res Commun 1999, 257(1):79-83.

7. Hajer GR, Van Haeften TW, Visseren FL: Adipose tissue dysfunction in obesity, diabetes, and vascular diseases. Eur Heart J 2008, 29(24):2959-2971.

8. Trujillo ME, Scherer PE: Adiponectin-journey from an adipocyte secretory protein to biomarker of the metabolic syndrome. J Intern Med 2005, 257(2):167-175

9. Lihn AS, Pedersen SB, Richelsen B: Adiponectin: action, regulation and association to insulin sensitivity. Obes Rev 2005, 6(1):13-21

10. Gil-Campos M, Canete RR, Gil A: Adiponectin, the missing link in insulin resistance and obesity. Clin Nutr 2004, 23(5):963-974.

11. Zhu W, Cheng KK, Vanhoutte PM, Lam KS, Xu A: Vascular effects of adiponectin: molecular mechanisms and potential therapeutic intervention. Clin Sci (Lond) 2008, 114(5):361-374.

12. Han SH, Quon MJ, Kim JA, Koh KK: Adiponectin and cardiovascular disease: response to therapeutic interventions. J Am Coll Cardiol 2007, 49(5):531-538

13. Hopkins TA, Ouchi N, Shibata R, Walsh K: Adiponectin actions in the cardiovascular system. Cardiovasc Res 2007, 74(1):11-18.

14. Yamauchi T, Kamon J, Ito Y, Tsuchida A, Yokomizo T, Kita S, Sugiyama T, Miyagishi M, Hara K, Tsunoda M, et al: Cloning of adiponectin receptors that mediate antidiabetic metabolic effects. Nature 2003, 423(6941):762-769.

15. Yamauchi T, Nio Y, Maki T, Kobayashi M, Takazawa T, Iwabu M, Okada-Iwabu M, Kawamoto S, Kubota N, Kubota T, et al: Targeted disruption of AdipoR1 and AdipoR2 causes abrogation of adiponectin binding and metabolic actions. Nat Med 2007, 13(3):332-339.

16. Heiker JT, Kosel D, Beck-Sickinger AG: Molecular mechanisms of signal transduction via adiponectin and adiponectin receptors. Biol Chem 2010, 391(9):1005-1018.

17. Mao X, Kikani CK, Riojas RA, Langlais $P$, Wang L, Ramos FJ, Fang Q, ChristRoberts CY, Hong JY, Kim RY, et al: APPL1 binds to adiponectin receptors and mediates adiponectin signalling and function. Nat Cell Biol 2006, 8(5):516-523.

18. Deepa SS, Dong LQ: APPL1: role in adiponectin signaling and beyond. Am J Physiol Endocrinol Metab 2009, 296(1):E22-E36.

19. Buechler C, Wanninger J, Neumeier M: Adiponectin receptor binding proteins-recent advances in elucidating adiponectin signalling pathways. FEBS Lett 2010, 584(20):4280-4286.

20. Hosch SE, Olefsky JM, Kim JJ: APPLied mechanics: uncovering how adiponectin modulates insulin action. Cell Metab 2006, 4(1):5-6.

21. Wang C, Xin X, Xiang R, Ramos FJ, Liu M, Lee HJ, Chen H, Mao X, Kikani CK Liu F, et al: Yin-Yang regulation of adiponectin signaling by APPL isoforms in muscle cells. J Biol Chem 2009, 284(46):31608-31615.

22. Chen H, Montagnani M, Funahashi T, Shimomura I, Quon MJ: Adiponectin stimulates production of nitric oxide in vascular endothelial cells. $J$ Biol Chem 2003, 278(45):45021-45026.

23. Hattori Y, Suzuki M, Hattori S, Kasai K: Globular adiponectin upregulates nitric oxide production in vascular endothelial cells. Diabetologia 2003, 46(11):1543-1549.

24. Cheng KK, Lam KS, Wang Y, Huang Y, Carling D, Wu D, Wong C, Xu A: Adiponectin-induced endothelial nitric oxide synthase activation and nitric oxide production are mediated by APPL1 in endothelial cells. Diabetes 2007, 56(5):1387-1394.

25. Xi W, Satoh H, Kase H, Suzuki K, Hattori Y: Stimulated HSP90 binding to eNOS and activation of the PI3-Akt pathway contribute to globular adiponectin-induced NO production: vasorelaxation in response to globular adiponectin. Biochem Biophys Res Commun 2005, 332(1):200-205.

26. Schmid PM, Resch M, Steege A, Fredersdorf-Hahn S, Stoelcker B, Birner C, Schach C, Buechler C, Riegger GA, Luchner A, et al: Globular and fulllength adiponectin induce NO-dependent vasodilation in resistance arteries of Zucker lean but not Zucker diabetic fatty rats. Am J Hypertens 2011, 24(3):270-277.

27. Cao Y, Tao L, Yuan Y, Jiao X, Lau WB, Wang Y, Christopher T, Lopez B, Chan $L$, Goldstein $B$, et al: Endothelial dysfunction in adiponectin deficiency and its mechanisms involved. J Mol Cell Cardiol 2009, 46(3):413-419. 
28. Deng G, Long Y, Yu YR, Li MR: Adiponectin directly improves endothelial dysfunction in obese rats through the AMPK-eNOS Pathway. Int J Obes (Lond) 2010, 34(1):165-171.

29. Ouchi N, Ohishi M, Kihara S, Funahashi T, Nakamura T, Nagaretani H, Kumada M, Ohashi K, Okamoto Y, Nishizawa H, et al: Association of hypoadiponectinemia with impaired vasoreactivity. Hypertension 2003, 42(3):231-234.

30. Quaile MP, Melich DH, Jordan HL, Nold JB, Chism JP, Polli JW, Smith GA, Rhodes MC: Toxicity and toxicokinetics of metformin in rats. Toxicol Appl Pharmacol 2010, 243(3):340-347.

31. Tian J, Wang J, Li Y, Villarreal D, Carhart R, Dong Y, Wen Y, Liu K: Endothelial function in patients with newly diagnosed type 2 diabetes receiving early intensive insulin therapy. Am J Hypertens 2012, 25(12):1242-1248.

32. Metais C, Forcheron F, Abdallah P, Basset A, Del Carmine P, Bricca G, Beylot M: Adiponectin receptors: expression in Zucker diabetic rats and effects of fenofibrate and metformin. Metabolism 2008, 57(7):946-953.

33. Sena CM, Matafome P, Louro T, Nunes E, Fernandes R, Seica RM: Metformin restores endothelial function in aorta of diabetic rats. $\mathrm{Br} J$ Pharmacol 2011, 163(2):424-437.

34. Sartoretto JL, Melo GA, Carvalho MH, Nigro D, Passaglia RT, Scavone C, Cuman RK, Fortes ZB: Metformin treatment restores the altered microvascular reactivity in neonatal streptozotocin-induced diabetic rats increasing NOS activity, but not NOS expression. Life Sci 2005, 77(21):2676-2689.

35. Fasshauer M, Klein J, Neumann S, Eszlinger M, Paschke R: Hormonal regulation of adiponectin gene expression in 3T3-L1 adipocytes. Biochem Biophys Res Commun 2002, 290(3):1084-1089.

36. Pereira Rl, Draznin B: Inhibition of the phosphatidylinositol 3'-kinase signaling pathway leads to decreased insulin-stimulated adiponectin secretion from 3T3-L1 adipocytes. Metabolism 2005, 54(12):1636-1643.

37. Blumer RM, Van Roomen CP, Meijer AJ, Houben-Weerts JH, Sauerwein HP, Dubbelhuis PF: Regulation of adiponectin secretion by insulin and amino acids in 3T3-L1 adipocytes. Metabolism 2008, 57(12):1655-1662.

38. Kadowaki T, Yamauchi T, Kubota N, Hara K, Ueki K, Tobe K: Adiponectin and adiponectin receptors in insulin resistance, diabetes, and the metabolic syndrome. J Clin Invest 2006, 116(7):1784-1792.

39. Mohlig M, Wegewitz U, Osterhoff M, Isken F, Ristow M, Pfeiffer AF, Spranger $\mathrm{J}$ : Insulin decreases human adiponectin plasma levels. Horm Metab Res 2002, 34(11-12):655-658.

40. Fujita H, Fujishima H, Koshimura J, Hosoba M, Yoshioka N, Shimotomai T, Morii T, Narita T, Kakei M, Ito S: Effects of antidiabetic treatment with metformin and insulin on serum and adipose tissue adiponectin levels in db/db mice. Endocr J 2005, 52(4):427-433.

41. Cui XB, Wang C, Li L, Fan D, Zhou Y, Wu D, Cui QH, Fu FY, Wu LL: Insulin decreases myocardial adiponectin receptor 1 expression via PI3K/Akt and FoxO1 pathway. Cardiovasc Res 2012, 93(1):69-78.

42. Zulian A, Cancello R, Girola A, Gilardini L, Alberti L, Croci M, Micheletto G, Danelli $P$, Invitti $C$ : In vitro and in vivo effects of metformin on human adipose tissue adiponectin. Obes Facts 2011, 4(1):27-33.

43. Hanefeld M, Pfutzner A, Forst T, Kleine I, Fuchs W: Double-blind, randomized, multicentre, and active comparator controlled investigation of the effect of pioglitazone, metformin, and the combination of both on cardiovascular risk in patients with type 2 diabetes receiving stable basal insulin therapy: the PIOCOMB study. Cardiovasc Diabetol 2011, 10:65.

44. Doogue MP, Begg EJ, Moore MP, Lunt H, Pemberton CJ, Zhang M: Metformin increases plasma ghrelin in Type 2 diabetes. $\mathrm{Br} J \mathrm{Clin}$ Pharmacol 2009, 68(6):875-882.

45. Tarkun I, Dikmen E, Cetinarslan B, Canturk Z: Impact of treatment with metformin on adipokines in patients with polycystic ovary syndrome. Eur Cytokine Netw 2010, 21(4):272-277.

46. Sofer E, Boaz M, Matas Z, Mashavi M, Shargorodsky M: Treatment with insulin sensitizer metformin improves arterial properties, metabolic parameters, and liver function in patients with nonalcoholic fatty liver disease: a randomized, placebo-controlled trial. Metabolism 2011, 60(9):1278-1284

47. Gomez-Diaz RA, Talavera JO, Pool EC, Ortiz-Navarrete FV, Solorzano-Santos F, Mondragon-Gonzalez R, Valladares-Salgado A, Cruz M, Aguilar-Salinas CA Wacher NH: Metformin decreases plasma resistin concentrations in pediatric patients with impaired glucose tolerance: a placebo-controlled randomized clinical trial. Metabolism 2012, 61(9):1247-1255.
48. Phillips SA, Ciaraldi TP, Kong AP, Bandukwala R, Aroda V, Carter L, Baxi S, Mudaliar SR, Henry RR: Modulation of circulating and adipose tissue adiponectin levels by antidiabetic therapy. Diabetes 2003, 52(3):667-674.

49. Adamia N, Virsaladze D, Charkviani N, Skhirtladze M, Khutsishvili M: Effect of metformin therapy on plasma adiponectin and leptin levels in obese and insulin resistant postmenopausal females with type 2 diabetes. Georgian Med News 2007, 145:52-55.

50. Mather KJ, Funahashi T, Matsuzawa Y, Edelstein S, Bray GA, Kahn SE, Crandall J, Marcovina S, Goldstein B, Goldberg R, et al: Adiponectin, change in adiponectin, and progression to diabetes in the Diabetes Prevention Program. Diabetes 2008, 57(4):980-986.

51. Steiner CA, Janez A, Jensterle M, Reisinger K, Forst T, Pfutzner A: Impact of treatment with rosiglitazone or metformin on biomarkers for insulin resistance and metabolic syndrome in patients with polycystic ovary syndrome. J Diabetes Sci Technol 2007, 1(2):211-217.

52. Sattar AA, Sattar R: Insulin-regulated expression of adiponectin receptors in muscle and fat cells. Cell Biol Int 2012, 36(12):1293-1297.

53. Sun X, He J, Mao C, Han R, Wang Z, Liu Y, Chen Y: Negative regulation of adiponectin receptor 1 promoter by insulin via a repressive nuclear inhibitory protein element. FEBS Lett 2008, 582(23-24):3401-3407.

54. Zanetti M, Barazzoni R, Stebel M, Roder E, Biolo G, Baralle FE, Cattin L, Guarnieri G: Dysregulation of the endothelial nitric oxide synthasesoluble guanylate cyclase pathway is normalized by insulin in the aorta of diabetic rat. Atherosclerosis 2005, 181(1):69-73.

55. Murthy SN, Pankey EA, Banka AA, Badejo AM Jr, Wekerle R, Vilija V, Izadpanah R, Kadowitz PJ, Fonseca VA: Effects of insulin detemir on balloon catheter injured carotid artery in Zucker fatty rats. J Diabetes Complications 2012, 26(6):470-475.

56. Matsumoto T, Noguchi E, Ishida K, Kobayashi T, Yamada N, Kamata K: Metformin normalizes endothelial function by suppressing vasoconstrictor prostanoids in mesenteric arteries from OLETF rats, a model of type 2 diabetes. Am J Physiol Heart Circ Physiol 2008, 295(3):H1165-H1176.

\section{doi:10.1186/1475-2840-12-46}

Cite this article as: Schmid et al: Antidiabetic treatment restores adiponectin serum levels and APPL1 expression, but does not improve adiponectin-induced vasodilation and endothelial dysfunction in Zucker diabetic fatty rats. Cardiovascular Diabetology 2013 12:46.

\section{Submit your next manuscript to BioMed Central and take full advantage of:}

- Convenient online submission

- Thorough peer review

- No space constraints or color figure charges

- Immediate publication on acceptance

- Inclusion in PubMed, CAS, Scopus and Google Scholar

- Research which is freely available for redistribution 